'Editor Emérito, Revista Médica de Chile. Miembro de Número, Academia Chilena de Medicina. Profesor Emérito, Universidad de Chile.

Texto basado en el homenaje rendido por la Academia Chilena de Medicina, en Sesión Ordinaria del 5 de mayo de 2021, y en documentos publicados en la página web www. academiachilenademedicina.cl

Conflictos de intereses: el autor de este homenaje integró el equipo de editores de la Revista Médica de Chile desde 1971. En 1996 sucedió al doctor Goic como editor jefe hasta febrero de 2016.

Correspondencia a: Dr. Humberto Reyes B. hreyes24@gmail.com

\section{Homenaje póstumo al Doctor Alejandro Goic (1929-2021), Editor Emérito}

\author{
HUMBERTO REYES BUDELOVSKY ${ }^{1}$
}

\section{A posthumous tribute to Alejandro Goic, M.D. (1929-2021), Editor Emeritus}

Alejandro Goic, M.D., son of Croatian immigrants, graduated as M.D. in 1955, studying at the Catholic University of Chile Medical School. After a residency in internal medicine, he followed post graduate studies in psychosomatic medicine at the University of Oklahoma and in gastroenterology at Harvard University. Upon his return to Chile he had a brilliant career as clinician and medical educator, becoming a leader and advisor in medical education, clinical ethics and public health. Elected Dean of the University of Chile School of Medicine (1986-1994), he promoted important changes in undergraduate studies as well as in Magister and PhD programs in Biomedical Sciences. During the difficult years of the military government intervention in Chilean universities, he was one of the leaders of critical opposition. In parallel he was chief editor of Revista Médica de Chile (1976-1996), improving the editorial process according to the recommendations of ICMJE and WAME. In 1989 he was elected member of the Chilean Academy of Medicine and became its President (2000-2010). He was awarded honors and membership in prominent national and foreign institutions. In 2006 he received the National Prize in Medicine, the highest medical distinction in Chile. His wise thinking and enthusiasm gave origin to several books that have become classics in Medicine and Medical Education, permeating our institutions.

(Rev Med Chile 2021; 149: 598-601)

Key words: Awards and Prizes; Centers, Academic Medical; Education, Medical; Faculty; Journalism, Medical; Medical Writings.
E 120 de abril de 2021 falleció el doctor Alejandro Goic Goic, una de las figuras más destacadas de la medicina nacional.

Hijo de inmigrantes croatas, nació en Antofagasta el 22 de junio de 1929. Su educación primaria y secundaria transcurrió en el Colegio San Pedro Nolasco, en Santiago. Cursó estudios de medicina en la Universidad Católica de Chile y en 1955 recibió el título de Médico-Cirujano, otorgado por la Universidad de Chile.

Se especializó en Medicina Interna en el Hospital del Salvador, con una beca del Ministerio de Salud. Cumplió la post beca en el Hospital de Temuco y regresó a Santiago, incorporándose a la planta médica del Servicio y Cátedra de Medicina del Hospital del Salvador, donde transcurrió la mayor parte de su carrera asistencial y docente. Desde un comienzo fue gratamente apreciado por sus alumnos, sus pares y por el profesor doctor Hernán Alessandri Rodríguez, su maestro y modelo clínico y docente. Becas internacionales le permitieron estadías de perfeccionamiento profesional en las Universidades de Oklahoma (Medicina Psicosomática) y Harvard (Gastroenterología). Al regresar a Chile reanudó sus actividades universitarias destacando sus condiciones de líder en el pensamiento y la acción, en temas de atención en salud y educación médica. 


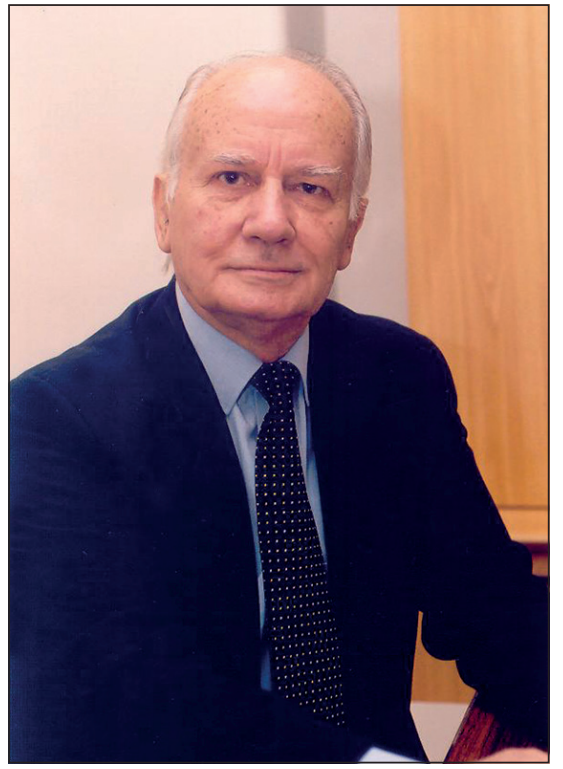

A consecuencias de la reforma universitaria, la Universidad de Chile fraccionó la Facultad de Medicina en cinco sedes y el doctor Goic fue elegido decano de la Facultad Oriente. A pocos años la Facultad fue reunificada y el doctor Goic fue elegido decano, durante dos períodos consecutivos (1986 a 1994).

Durante su decanato estimuló la modernización de los estudios de las carreras de la salud, en pre y post título, ampliando los programas de Magister y creando el Doctorado en Ciencias Biomédicas. La docencia de ética médica fue una de sus principales preocupaciones, incorporándola como disciplina regular en el plan de estudios, junto con temas históricos y humanísticos. Impulsó la implementación de técnicas computacionales en la Biblioteca Central de la Facultad y consiguió la adscripción a ella del Museo Nacional de Medicina. Para concretar estas tareas supo conquistar la colaboración entusiasta de muchos expertos.

Tenía una visión optimista de la vida, mostrándose afable y respetuoso de los demás, cualquiera fuese su condición social o económica. Supo hacerse respetar sin necesidad de recurrir al autoritarismo. Era cordial, siempre receptivo para quienes requiriesen su consejo o ayuda, ameno en sus conversaciones, matizadas con toques de sano humor. Sus ideales eran claros y trataba de cumplirlos con entusiasmo y a plena cabalidad, defendiéndolos con honestidad y firmeza.

Frente a la catastrófica intervención gubernamental sufrida por la Universidad de Chile y otras (1973-1990), el doctor Goic destacó por un liderazgo claro y valeroso al expresar sus críticas, públicamente, convirtiéndose en uno de los referentes de la visión universitaria durante el período que se conoció como "la rebelión de los decanos".

Desde muy joven se interesó por el progreso de la Revista Médica de Chile, incorporándose a su equipo editorial a mediados de la década de 1960. Fue nombrado editor jefe en 1970. Durante los veintiséis años en que ejerció este cargo (el período más prolongado en la historia de la Revista) impulsó con tenacidad y eficiencia el progreso del proceso editorial, consiguiendo la inclusión de la Revista en las principales bases de datos internacionales de revistas científicas, consolidando su posición de revista médica emblemática de nuestro país. En 1970 la Revista aparecía con cuatro a cinco meses de retraso, lapso que logró reducir eficazmente. Cada número tenía setenta a ochenta páginas, lo que fue necesario aumentar (actualmente ciento setenta o más), porque el flujo de manuscritos sometidos a selección creció junto con el prestigio de la revista. Se implantó la revisión de los manuscritos por especialistas o "pares" externos, antes de una decisión definitiva por los editores, y se aprovechó este sistema para estimular un rol educacional para la elaboración de manuscritos y su revisión crítica. La nuestra fue una de las primeras revistas médicas en el mundo que adhirió a la propuesta de adoptar un sistema uniforme para el formato de los manuscritos, acorde con lo propuesto por la National Library of Medicine de los EE UU de NA, lo que contribuyó a abrirle camino para ser clasificada en la "corriente principal" de las revistas científicas. En el ámbito nacional, propició profesionalizar la función de los editores, el personal de secretaría y apoyo, conformando un equipo con vocación de ser útil para los lectores de la revista y los autores de manuscritos. Al cesar en su cargo, el Directorio de la Sociedad Médica de Santiago le confirió el rango honorífico de "Editor Emérito".

El prestigio y ascendiente adquirido en educación médica respaldaron su elección como presidente de la Asociación Chilena de Facultades de Medicina, su membresía en el Consejo Superior de la Universidad de Chile, en el Consejo Superior 
de Educación del Ministerio de Educación, y su participación en numerosos comités de estudio sobre temas de desarrollo universitario, profesional, gremial, de atención médica y salud pública, y de ética clínica, asesorando a las universidades, la Sociedad Médica de Santiago, el Colegio Médico de Chile.

La claridad de su pensamiento clínico y la convicción de que la semiología es la herramienta básica del actuar médico lo impulsaron a diseñar y dirigir la edición de "Semiología Médica", libro que reúne la experiencia de connotados profesionales de nuestro país, se ha publicado ya en cuatro ediciones y -en palabras del doctor Goic- "ha sido acogido como texto de estudio por generaciones de jóvenes estudiantes de medicina en nuestro país y en otras latitudes".

Su vasta cultura lo estimuló a publicar libros que son referentes bibliográficos apreciados: "El fin de la medicina", "Ensayo sobre la Educación Médica en Chile", "Pensamiento universitario", "Grandes médicos humanistas", "El paciente escindido", "La herencia de Hipócrates", "Conversaciones con Hipócrates”. En 2019 apareció "Columnas ciudadanas", una recopilación de artículos publicados desde 1974 en diversos órganos de prensa, donde había expresado sus reflexiones sobre materias relacionadas estrechamente con el acontecer nacional. En ellos dejó en claro la profundidad de su pensamiento, adoptando una posición definida y fundamentada en temas que abarcan el origen de la vida humana y el aborto terapéutico, la muerte cerebral y los trasplantes de órganos, el concepto de "eutanasia", opciones de justificación a las huelgas de médicos y los "turnos éticos", y muchos otros, resaltando la complejidad que tienen las decisiones éticas durante el ejercicio de la medicina clínica.

Numerosas sociedades médicas científicas lo nombraron miembro activo u honorario, en Chile y otros países de las Américas y España.

En 1989 ingresó como Miembro de Número en la Academia Chilena de Medicina, institución que presidió entre los años 2000 y 2010 , impulsando -entre otras iniciativas- la formación de grupos de estudio con participación de académicos y expertos externos invitados, que elaboraron documentos señeros expresando la opinión de la Academia sobre temas contingentes en educación médica, salud pública, ética profesional, dirigidos a la opinión pública y a las autoridades pertinentes.
Entre las distinciones que recibió destacan: "Maestro de la Medicina Interna Chilena"; "Maestro de la Medicina Latinoamericana"; "Medalla Rector Juvenal Hernández Jaque" y "Profesor Emérito" de la Universidad de Chile; "Condecoración de la Orden de la Cruz del Sur, en Grado de Collar" del Ministerio de Salud de Chile; "Medalla Centenario" de la Organización Panamericana de la Salud; "Cruz de Oro" de la Asociación Latinoamericana de Academias Nacionales de Medicina; "Miembro Honorario" de la Academia Científica de Estudiantes de Medicina de la Universidad de Chile.

En el año 2006 recibió el Premio Nacional de Medicina. Difícilmente se podría sintetizar su vida con mayor precisión que lo expresado por él mismo al agradecer ese premio: “... haberme esforzado por ejercer la medicina en forma responsable y humanitaria, y no haber restado mi participación en ninguna iniciativa que contribuyera al progreso de la medicina y la educación médica...con la necesaria dosis de entusiasmo, y tal vez pasión, que he puesto en todas las actividades que he emprendido en mi vida profesional y académica".

En este homenaje póstumo al doctor Alejandro Goic no debemos omitir sus méritos como esposo, padre, abuelo y bisabuelo. Casado con Carmen Jerez Horta, a quien conoció en su juventud, siendo ambos dirigentes de organizaciones estudiantiles, formaron una familia con cinco hijos: Alejandro, Andrea, Juan, Carmen y Paulina, destacados en el mundo de las artes y las humanidades. Su esposa falleció a temprana edad, mientras la familia se expandió con cuatro nietos y una bisnieta.

El doctor Goic, cuyos padres pertenecieron a distintas familias que emigraron desde la isla Brač a Punta Arenas, estaba muy orgulloso del origen croata de sus ancestros y realizó una ímproba

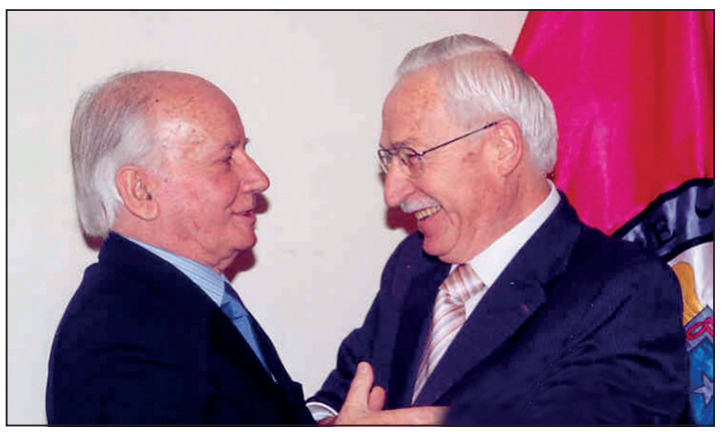


labor reuniendo testimonios, documentos y fotografías para resumir las biografías de decenas de familiares y otras personas que llegaron a Chile como emigrantes desde Croacia, en un libro que tituló "Del Adriático al Sur del Pacífico", con la intención expresa de "rendir una suerte de tributo espiritual a los primeros emigrantes dálmatas, hombres y mujeres de acendrada fe religiosa, cuyos restos descansan hoy en tierra chilena, en la paz del Señor". Con ellos se ha reunido ahora Alejandro Goic Goic, un hombre de bien que hizo muchas cosas en su vida, convirtiéndose en una persona cuyo recuerdo quedará inserto en la historia de nuestras instituciones. 